\title{
The Adaptation of Suaeda physophora Seedlings to Salinity and Drought Environments
}

\author{
W.W. Zhao, T.T. Fu, F.X. Wang, Y.G. Xu \& J. Song* \\ Key Laboratory of Plant Stress, College of Life Science, Shandong Normal University, Jinan 250014, China \\ * author for correspondence
}

\begin{abstract}
We investigated the effect of combined salinity and drought stress on ion accumulation, membrane permeability in leaves, and seedling survival and shoot dry weight of Suaeda physophora seedlings after they were rewatered. The results showed that drought stress increased leaf $\mathrm{Na}^{+}$and $\mathrm{Cl}^{-}$content, especially at $400 \mathrm{mmol} \cdot \mathrm{L}^{-1} \mathrm{NaCl}$ pretreatment, while drought treatment had no effect on leaf $\mathrm{K}^{+}$content after seedlings were pretreated with either 1 or $400 \mathrm{mmol} \cdot \mathrm{L}^{-1} \mathrm{NaCl}$. Shoot dry weight of seedlings decreased during drought treatment compared to control (without drought treatment) regardless the concentrations of salinity after seedlings were rewatered. Drought treatment had less adverse effect on the seedling and leaf survival in seedlings pretreated at $400 \mathrm{mmol} \cdot \mathrm{L}^{-1} \mathrm{NaCl}$ than at $1 \mathrm{mmol} \cdot \mathrm{L}^{-1} \mathrm{NaCl}$ after seedlings were rewatered. The present results indicate that seedlings of $S$. physophora pretreated with salinity can increase seedling survival, and this can help them to adapt to combined salinity and drought stress in arid areas.
\end{abstract}

KEYWORD: Suaeda physophora; Salinity; Drought; Shoot dry weight

\section{INTRODUCTION}

Drought and salinization are two major problems which affect the global environment and economic development. Suaeda physophora Pall. is leafsucculent euhalophytic shrub growing in highly salinized lands. The species is common in saline lands or in the Zhunger Basin, which is located in Xinjiang, a northwest province of China. Annual evaporation is 10 times more than annual precipitation in this region, and it is one of the driest regions in the Eurasian continent (Song et al. 2006a). The percentage of unsaturated fatty acid in seed oil of $S$. physophora was $96 \%$, in which linoleic acid was about $75 \%(\mathrm{Mu}$ et al. 2006). Therefore, the species can be used in saline agriculture. The species has high salt tolerance during stages of seed germination and seedling growth (Wang et al. 2005; Song et al. 2006a,b). Euhalophytes always accumulate high concentration of inorganic ions to lower osmotic potential, thus they can absorb water from saline soils to ensure growth (Song, et al. 2006a; Liu et al. 2010). S. Physophora is a typical euhalophyte in arid areas (Song et al. 2006a,b). However, the mechanism how the species adapt to combined salinity and drought stress is unclear.

\section{MATERIALS AND METHODS}

\subsection{Plant material}

Seeds were collected from plants in Xinjiang province of northwest China in October 2012. Dry seeds were stored in a refrigerator at $<4^{\circ} \mathrm{C}$ before being used.

\subsubsection{Plant culture and experimental design}

Seeds of $S$. physophora were sown in plastic pots filled with river sand. Nutrient solutions of a fifth concentration of Hoagland were supplied dairy, and the $\mathrm{pH}$ was adjusted to $6.6 \pm 0.1$ with $\mathrm{KOH}$ and $\mathrm{H}_{2} \mathrm{SO}_{4}$. The amount of $150 \mathrm{ml}$ nutrient solutions was supplied every day, an amount that flushed the drained pots. Ten seedlings with 5 to 6 leaves were left in each pot. Seedlings with 8 to 9 leaves were treated with $1 \mathrm{mmol} \cdot \mathrm{L}^{-1}$ (as control) or $400 \mathrm{mmol} \cdot \mathrm{L}^{-1}$ $\mathrm{NaCl}$. To avoid osmotic shock, $400 \mathrm{mmol} \cdot \mathrm{L}^{-1} \mathrm{NaCl}$ was applied gradually by adding $50 \mathrm{mmol} \cdot \mathrm{L}^{-1}$ per day. Two weeks after the final addition of $\mathrm{NaCl}, 3$ pots were watered as control, and the other 3 pots were not watered at 1 or $400 \mathrm{mmol} \cdot \mathrm{L}^{-1} \mathrm{NaCl}$. When most of the seedlings wilted (7days for $1 \mathrm{mmol} \cdot \mathrm{L}^{-1} \mathrm{NaCl}$ treatment, and 14days for $400 \mathrm{mmol} \cdot \mathrm{L}^{-1} \mathrm{NaCl}$ treatment), ion content and relative conductivity in leaves were determined. Meanwhile, wilted seedlings which were not watered were rewatered 
with original solutions for another 8days. Then seedling and leaf survival and shoot dry weight were determined.

\subsubsection{Determination of ion content}

The leaves were cleaned with distilled water, and $0.15 \mathrm{~g}$ fresh sample was boiled in distilled water for 12h. After the solution was filtered, the concentrations of $\mathrm{Na}^{+}$and $\mathrm{K}^{+}$were determined by flame photometer (Flame Photometer 410, Sherwood Scientific Ltd, Cambridge, UK), $\mathrm{Cl}^{-}$ content was determined by ion-chromatographic analyzer (ICS-1100 Ion-chromatographic Analyzer, Thermofisher Scientic Company, USA).

\subsubsection{Determination of relative conductivity}

A $0.15 \mathrm{~g}$ fresh leaves were washed with double distilled water, and relative conductivity was determined as described by Leul and Zhou (1999).

\subsubsection{Seedling and leaf survival after seedlings were rewatered}

Seedling and leaf survival percentage were determined based on the number that survived during the combined salinity and drought stress, and calculated according to the formula as follows:

Leaf survival $=n / m \times 100$

Seedling survival $=d / f \times 100$

Where $n$ was the leaf survival number after seedlings were rewatered, and $m$ was the total leaf number; $d$ was the seedling survival number after seedlings were rewatered, and $f$ was the total seedling number.

\subsubsection{Shoot dry weight after seedlings were rewatered}

At the end of the study, shoots were harvested from each of six replicate pots at both concentrations of $\mathrm{NaCl}$. The shoots were air-dried and weighed.

\subsubsection{Statistical analysis}

Data were subjected to a Two-way ANOVA using the SAS 6.12 software. Treatment means were compared by LSD at $\mathrm{P}=0.05$.

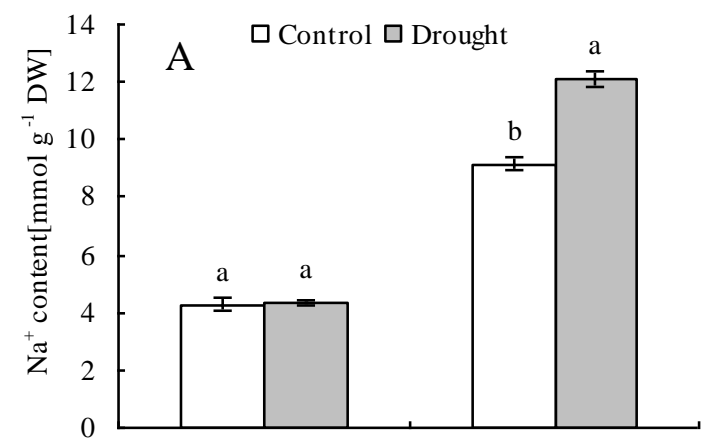

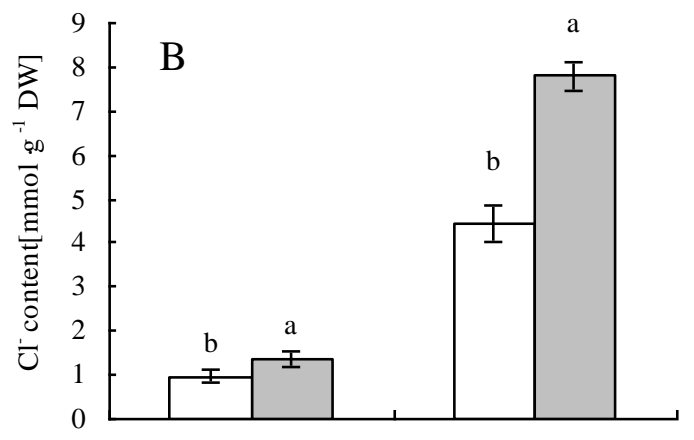
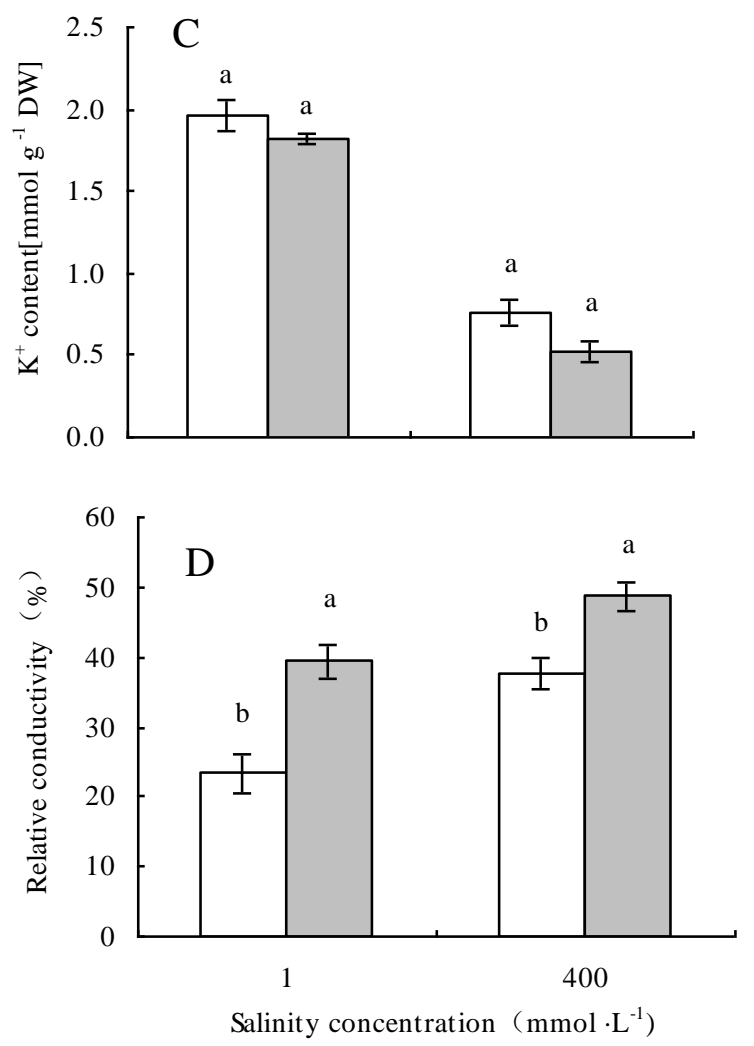

Fig. $1 \mathrm{Na}^{+}, \mathrm{K}^{+}, \mathrm{Cl}^{-}$concentration and relative conductivity in leaves of $S$. physophora seedlings after combined salinity and drought treatment. Within each $\mathrm{NaCl}$ treatment, means with different letters are significantly different at $\mathrm{P}<0.05$. Vertical bars represent standard errors $(n=3)$.

\section{RESULTS}

3.1 Effect of combined salinity and drought stress on inorganic ion and relative conductivity in leaves

The concentration of $\mathrm{Na}^{+}$and $\mathrm{Cl}^{-}$increased under drought stress, especially at $400 \mathrm{mmol} \cdot \mathrm{L}^{-1} \mathrm{NaCl}$ ( Figure $1 \mathrm{~A}, \mathrm{~B}$ ) while drought had no effect on $\mathrm{K}^{+}$ concentration regardless of $\mathrm{NaCl}$ treatment (Figure $1 \mathrm{C})$.

Drought treatment increased the relative conductivity of leaves at both concentrations of $\mathrm{NaCl}$, especially at $1 \mathrm{mmol} \cdot \mathrm{L}^{-1} \mathrm{NaCl}$. The relative conductivity of leaves with the drought treatment was 1.7 and 1.3 times in 1 and $400 \mathrm{mmol} \cdot \mathrm{L}^{-1} \mathrm{NaCl}$ respectively of that in leaves of control (Figure 1D). 

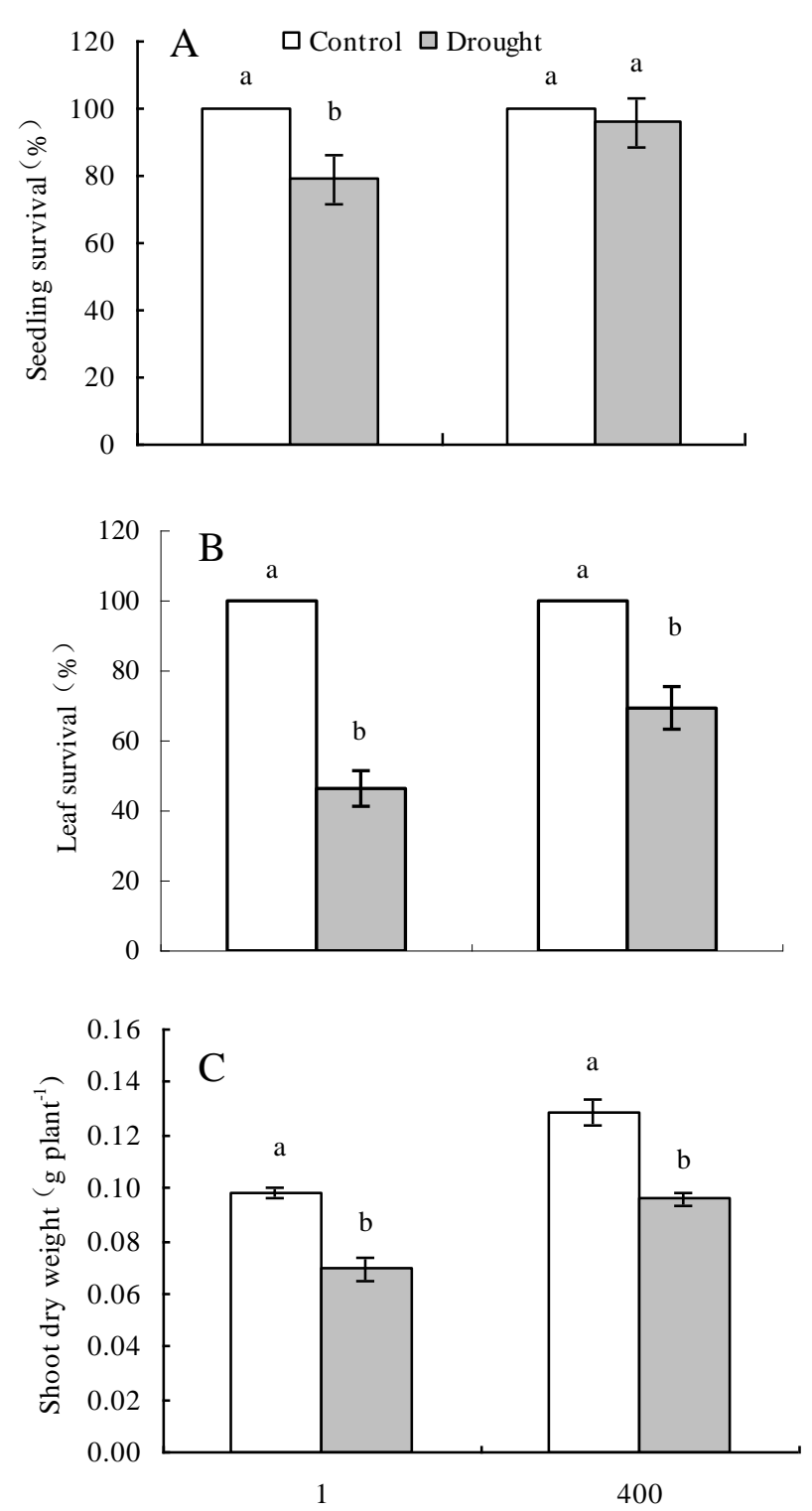

Salinity concentration $\left(\mathrm{mmol} \cdot \mathrm{L}^{-1}\right)$

Fig. 2 Seedling and leaf survival and shoot dry weight after $S$. physophora seedlings were rewatered. Within each $\mathrm{NaCl}$ treatment, means with different letters are significantly different at $\mathrm{P}<0.05$. Vertical bars represent standard errors $(n=3)$.

\subsection{Effect of combined salinity and drought stress on seedling and leaf survival and shoot dry weight}

Seedling survival pretreated with $1 \mathrm{mmol} \cdot \mathrm{L}^{-1} \mathrm{NaCl}$ was decreased compared to the control, while the value that pretreated with $400 \mathrm{mmol} \cdot \mathrm{L}^{-1} \mathrm{NaCl}$ had no significance difference after seedlings were rewatered (Figure 2A). The similar trend was shown in leaf survival (Figure 2B).

Shoot dry weight decreased at either 1 or 400 $\mathrm{mmol} \cdot \mathrm{L}^{-1} \mathrm{NaCl}$ pretreatment after seedlings were rewatered (Figure 2C).
Table 1 Results of two-way ANOVA of characteristics of ion content and relative conductivity in leaves of $S$. physophora seedlings after combined salinity and drought treatment; and seedling and leaf survival, and shoot dry weight of $S$. physophora seedlings after seedlings were rewatered $(*, * *, * * *$ Denotes significant difference at $P<0.05, P<0.001$ and $P<$ 0.001 , respectively, ${ }^{\text {ns }}$ denotes no significant difference. Data represent $F$ values).

\begin{tabular}{|l|c|c|c|}
\hline Independent variable & Salinity & Drought & $\begin{array}{c}\text { Salinity } \times \\
\text { Drought }\end{array}$ \\
\hline $\mathrm{Na}^{+}$content & $2041.41^{* * *}$ & $113.24 * * *$ & $103.45^{* * *}$ \\
\hline $\mathrm{K}^{+}$content & $890.05 * * *$ & $20.84 * *$ & $1.11^{\mathrm{ns}}$ \\
\hline $\mathrm{Cl}^{-}$content & $755.44 * * *$ & $107.65 * * *$ & $67.13^{* * *}$ \\
\hline Relative conductivity & $52.40^{* * *}$ & $69.11^{* * *}$ & $2.43^{\mathrm{ns}}$ \\
\hline Shoot dry weight & $126.51 * * *$ & $148.62^{* * *}$ & $0.67^{\mathrm{ns}}$ \\
\hline Seedling survival & $11.73^{*}$ & $26.28^{* *}$ & $11.73^{*}$ \\
\hline Leaf survival & $35.67 * *$ & $478.07^{* * *}$ & $35.67 * *$ \\
\hline
\end{tabular}

\section{DISCUSSION}

Gao et al. (2009) found that S. physophora has high tolerance to salinity, but the mechanism was not clear. Euhalophytes always accumulate high concentration of inorganic ions to increase the ability of osmotic adjustment (Song et al. 2006a, b). A serious of studies have shown that $\mathrm{K}^{+}$was essential to maintain the homeostasis of ions within plant cells (Song et al. 2006a), enzyme activation and protein synthesis (Zhu et al. 1998). Therefore, the stabilization of $\mathrm{K}^{+}$under drought stress was important for $S$. physophora seedlings which occurs in saline and arid regions. In addition, $\mathrm{Na}^{+}$and $\mathrm{Cl}^{-}$ increased under drought condition. Increased $\mathrm{Na}^{+}$ and $\mathrm{Cl}^{-}$may decrease the osmotic potential, which can help plants to absorb water from saline soils. This may be one of the important reasons why $S$. physophora seedlings can survive saline and arid environments.

Both salt and drought stresses can increase the membrane permeability (Lutts et al. 1996). In the present study, drought stress increased the relative conductivity of leaves regardless of the concentration of salinity ( 1 or $400 \mathrm{mmol} \cdot \mathrm{L}^{-1} \mathrm{NaCl}$ ). However, under drought condition seedlings pretreated with $400 \mathrm{mmol} \cdot \mathrm{L}^{-1} \mathrm{NaCl}$ seemed to have a lighter membrane damage in their leaves than in seedlings pretreated with $1 \mathrm{mmol} \cdot \mathrm{L}^{-1} \mathrm{NaCl}$. This was consistent with the result that seedlings pretreated with $400 \mathrm{mmol} \cdot \mathrm{L}^{-1} \mathrm{NaCl}$ had a higher seedling and leaf survival percentage than seedlings pretreated with $1 \mathrm{mmol} \cdot \mathrm{L}^{-1} \mathrm{NaCl}$. Sui et al. (2010) found that the content of unsaturated fatty acids in the euhalophyte Suaeda salsa increased by salt stress, and the increase of unsaturated fatty acids in membrane lipids can increase the photosystem tolerance to salt stress. Whether $400 \mathrm{mmol} \cdot \mathrm{L}^{-1} \mathrm{NaCl}$ pretreatment can affect the structure of membranes, and the relationship between the change of 
membranes structure and the seedling and leaf survival after seedlings were rewatered remains to be further studied.

The present results showed that seedlings of $S$. physophora pretreated with salinity can increase seedling survival, and this can help seedlings to adapt to combined salinity and drought stress in arid areas. This was consistent with the result in $S$. salsa (Huang et al. 2008). More important, seedlings wilted 7 days after drought treatment for $1 \mathrm{mmol} \cdot \mathrm{L}^{-1}$ $\mathrm{NaCl}$ pretreatment, but it was 14 days for 400 $\mathrm{mmol} \cdot \mathrm{L}^{-1} \mathrm{NaCl}$ pretreatment. This means seedlings pretreated with $400 \mathrm{mmol} \cdot \mathrm{L}^{-1} \mathrm{NaCl}$ had a higher resistance to drought stress than those pretreated with $1 \mathrm{mmol} \cdot \mathrm{L}^{-1} \mathrm{NaCl}$. In conclusion, seedlings of $S$. physophora pretreated with salinity can increase seedling survival, and this can help seedlings to adapt to combined salinity and drought stress in arid regions.

\section{ACKNOWLEDGMENTS}

The financial support from National Natural Science Research Foundation of China (31370420), the Natural Science Research Foundation of Shandong Province (ZR2010CM005), and the Program for Scientific Research Innovation Team in Colleges and Universities of Shandong Province is greatly appreciated.

\section{REFERENCES}

[1] Gao, B., Song, J., Liu, J.P., Shi, G.W., Fan, H., Zhao, K.F. \& Wang, B.S. 2009. Seedling emergence and salt tolerance of Suaeda physophora Pall. under salt stress. Acta Ecologica Sinic 29(11): 6131-6135 [in Chinese].
[2] Huang, W., Li, Z.G., Qiao, H.L., Li, C.Z. \& Liu, X.J. 2008. Interactive effect of sodium chloride and drought on growth and osmotica of Suaesa salsa. Chinese Journal of Eco-Agriculture 16(1): 173-178 [in Chinese].

[3] Leul, M. \& Zhou, W.J. 1999. Alleviation of waterlogging damage in winter rape by uniconazole application: effects on enzyme activity, lipid peroxidation, and membrane integrity. Journal of Plant Growth Regulation 18: 9-14.

[4] Liu, J.P., Gao, B., Li, X., Song, J., Fan, H., Wang, B.S. \& Zhao K.F. 2010. The effects of salinity and drought interaction on seed germination and seedling growth of suaeda salsa L. from different habitats. Acta Ecologica Sinica 30(20): 5485-5490 [in Chinese].

[5] Lutts, S., Kinet, J.M. \& Bouharmont, J. 1996. NaClinduced senescence in leaves of rice (Oryza sativa L.) cultivars differing in salinity resistance. Annals of Botany 78: 389-398.

[6] Mu, S.Y., Cheng, Z.M., Bao, Q., Yin, L.K. \& Pan, H.X. 2006. Analysis on the composition of fatty acids from seed oil of Suaeda physophora Pall.using GC/MS. Arid Zone Research 23(3):475-477 [in Chinese].

[7] Song, J., Feng, G., Tian, C.Y. \& Zhang, F.S. 2006 a. Osmotic adjustment traits of Suaeda physophora, Haloxylon Ammodendron and Haloxylon persicum in field or controlled conditions. Plant Science 170: 113-119.

[8] Song, J., Ding, X.D., Feng, G. \& Zhang, F.S. 2006 b. Nutritional and osmotic roles of nitrate in a euhalophyte and xerophyte in saline conditions. New Phytologist 171: 357-366.

[9] Sui, N., Li, M., Li, K. \& Wang, B.S. 2010. Increase in unsaturated fatty acids in membrane lipids of Suaeda salsa L. enhances protection of PSII under high salinity. Photosynthetica 48(4): 623-629.

[10] Wang, L., Tian, C.Y., Zhang, D.Y. \& Zhou, Z.B. 2005. Effects of illumination, temperature and salinity on the germination of Suaeda physophore Pall. seeds. Arid Land Geography 28(5): 670-674 [in Chinese].

[11] Zhu, J.K., Liu, J.P. \& Xiong, L.M. 1998. Genetic analysis of salt tolerance in Arabidopsis: evidence for a critical role of potassium nutrition. The Plant Cell 10: 1181-1191. 